\title{
Temporal trends of TAVI treatment characteristics in high volume centers in Germany 2013-2020
}

\author{
Victor Mauri ${ }^{1}$ - Mohamed Abdel-Wahab ${ }^{2} \cdot$ Sabine Bleiziffer $^{3} \cdot$ Verena Veulemans $^{4} \cdot$ Alexander Sedaghat $^{5}$. \\ Matti Adam ${ }^{1} \cdot$ Georg Nickenig ${ }^{5} \cdot$ Malte Kelm $^{4} \cdot$ Holger Thiele $^{2} \cdot$ Stephan Baldus $^{1} \cdot$ Tanja K. Rudolph $^{6}$
}

Received: 22 July 2021 / Accepted: 25 October 2021 / Published online: 9 November 2021

(c) The Author(s) 2021

\section{Abstract}

Objective To assess temporal trends of patient baseline characteristics, risk profile and outcome of transcatheter aortic valve implantation (TAVI) between 2013 and 2020.

Background Guideline recommendations and increasing confidence in TAVI therapy may have changed the selection of TAVI patients.

Methods Baseline risk profile and VARC-2 outcome of 15,344 patients undergoing TAVI at 5 high volume centers in Germany over the time period 2013-2020 was analyzed.

Results Over the 8 years, annual TAVI volumes more than doubled from 1071 in 2013 to 2996 in 2020. The baseline surgical risk estimated by the Society of Thoracic Surgeons (STS) score declined from 7.2 $\pm 6.2 \%$ to $4.6 \pm 3.7 \%(P<0.001)$ as a consequence of lower comorbidity burden, whereas mean age remained unchanged (2013 81.0 $\pm 6.1 ; 2020$ 80.8 \pm 6.4 ; $P=0.976$ ) with patients $\geq 80$ years accounting for about two-third of the treated cohort.

Periprocedural complications including bleeding (2013 24.5\%; $202012.1 \% ; P<0.001)$, vascular complications (2013 20.7\%; $202011.7 \%$; $P<0.001)$ and new permanent pacemaker implantation $(201320.1 \%$; $202013.8 \%, P<0.001)$ decreased significantly. Similarly, the 30-day mortality decreased from $5.4 \%$ to $2.1 \%(P<0.001)$, but remained high in high-risk patients (STS > 8\% 2013 7.5\%; $20206.9 \% ; P=0.778$ ).

Conclusion From 2013 to 2020, mortality and burden of complications following TAVI procedure significantly decreased in a large multicenter registry from Germany. Proportion of elderly patients remained stable, while the surgical risk profile decreased.

\section{Graphical abstract}

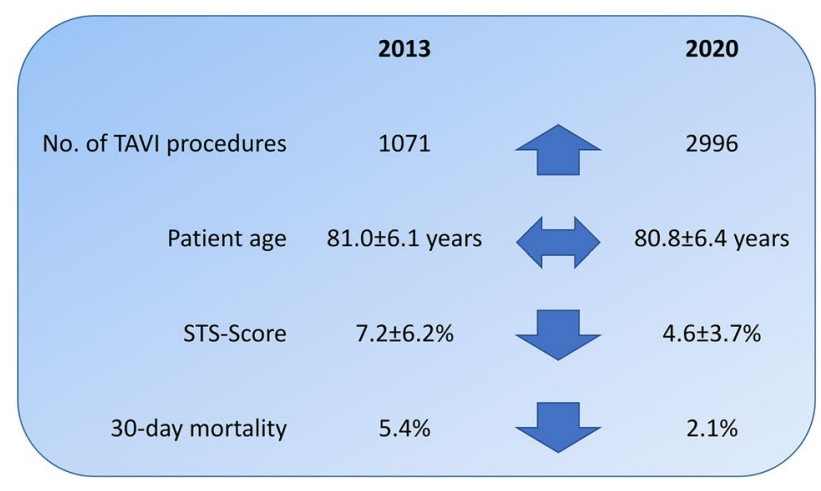

Keywords TAVI $\cdot$ Low risk $\cdot$ Aortic stenosis

Victor Mauri

victor.mauri@uk-koeln.de

Extended author information available on the last page of the article 


\section{Introduction}

Transcatheter aortic valve implantation (TAVI) has changed the treatment options for patients with symptomatic severe aortic stenosis fundamentally. TAVI was initially reserved for inoperable patients. Based on the evidence from the PARTNER 1A and CoreValve highrisk trial TAVI became the standard treatment option in patients with aortic stenosis and a high surgical risk based on the EuroSCORE or STS score [1,2]. The ESC/EACTS guidelines for the management of valvular heart disease published in 2017 already recommended TAVI even in intermediate risk patients taking into account the results from the PARTNER II trial and the SURTAVI trial [3-5]. Since the EuroSCORE and STS score have been proven to perform poorly in TAVI populations, these guidelines suggest that the decision for TAVI should also be based on individual risk factors not covered by the scores and on the age of the patient [6]. Following these recommendations, the individual clinical judgement and patient age became increasingly important factors for the decision to undergo surgical or interventional treatment. Furthermore, the role of the heart team for individual decision making was clearly highlighted [3].

Due to growing expertise in implantation technique as well as higher safety and efficacy in the latest TAVI devices, complication rate significantly decreased over the last decade, whereas procedural success and outcome markedly improved $[7,8]$.

In this context, German national guidelines decreased the age limit, from initially 85 years to currently 75 years in low-risk patients, making the therapy potentially available to a broader patient collective [9].

However, it has not been investigated so far, whether the recommendations of the guidelines and/or the increasing confidence in TAVI therapy really impacts the selection and outcome of patients undergoing the procedure. We therefore sought to investigate the trends of baseline characteristics mainly focusing on age and surgical risk of a large all-comers patient cohort undergoing TAVI in five high volume TAVI centers in Germany from 2013 to 2020.

\section{Methods}

All 15,344 consecutive patients undergoing TAVI for severe native aortic stenosis between January 2013 and December 2020 at 5 high volume centers in Germany (University Hospital Bonn, University Hospital Cologne, University Hospital Düsseldorf, Heart Center Leipzig at University of Leipzig, and Heart and Diabetes Center
Bad Oeynhausen) were analyzed. Data were collected prospectively within the respective institutional registries and analyzed retrospectively with approval of the institutional review board of the respective academic center. The study complied with the Declaration of Helsinki. Central analysis was based on pseudonymized data. Eligibility of the individual candidate for TAVI was decided within the local institutional multidisciplinary heart team. Temporal trends of patient baseline characteristics as well as procedural outcomes and 30-day mortality were analyzed. Subgroups based on age ( $<75$ years; $75-80$ years; $\geq 80$ years) and predicted surgical risk (STS-Score low: $<4 \%$; intermediate $4-8 \%$; high $\geq 8 \%$ ) were analyzed. Procedural outcomes were reported according to the VARC-2 consensus [10]. Risk-score calculation as well as clinical endpoints were site reported.

\section{Statistical analysis}

Continuous variables are presented as mean \pm standard deviation, categorical variables as frequencies and percentages. Analysis of categorical variables was performed with the Chi square or Fisher exact test. Continuous variables were analyzed with the Kruskal-Wallis test. Two-sided $P$ values $<0.05$ were considered statistically significant. All statistical analyses were performed with IBM SPSS Statistics, Version 27.

\section{Results}

\section{Age and predicted surgical risk}

In this analysis, a total of 15,344 patients undergoing TAVI from 2013 to 2020 were included. The annual number of patients treated with TAVI increased steadily from 1071 in 2013 to 2996 in 2020. Mean age remained stable during the observational period (mean age $81.0 \pm 6.1$ years; $P=0.680)$ as did the percentage of the pre-defined age groups ( $<75$ years, $75-80$ years and $\geq 80$ years). The main age group treated by TAVI was the group $\geq 80$ years accounting for approximately $65 \%$ of all patients (Fig. 1A, B). The predicted surgical risk as assessed by the STS score (2013 $7.2 \pm 6.2 \%, 20204.6 \pm 3.7 \% ; P<0.001)$ and the EuroScore II $(20137.4 \pm 6.7 \%, 20205.2 \pm 5.3 \%$; $P<0.001)$ steadily decreased from 2013 to 2020 (Fig. 1C). Looking at the three pre-defined STS score risk groups (low $<4 \%$, intermediate $4-8 \%$ and high $\geq 8 \%$ ) there was a significant increase of low-risk patients (2013 33.5\% to $202058.0 \%$; $P<0.001$; Fig. 1D). Although the proportion of high-risk patients decreased, the absolute number remained stable over the study period. This finding was observed consistently in all pre-defined age groups ( $P<0.001$ for all; Fig. 2$)$. 
A

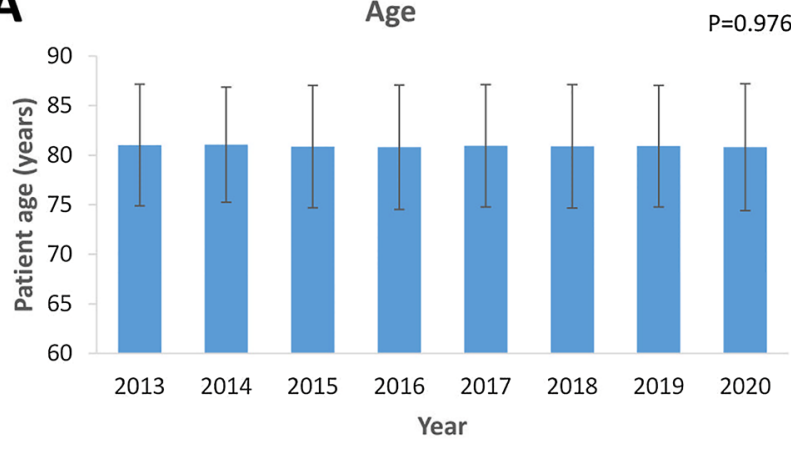

C

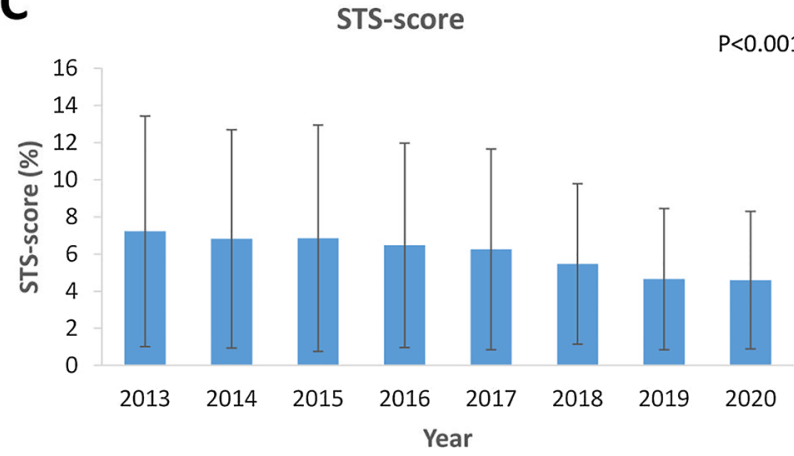

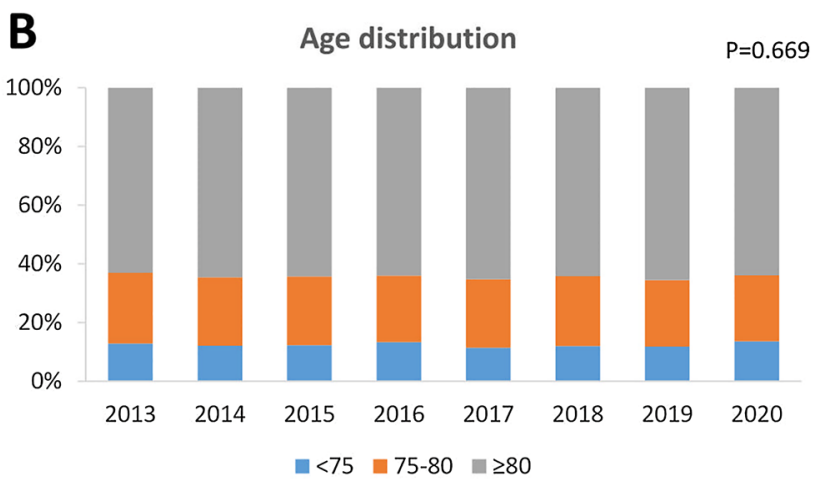

D

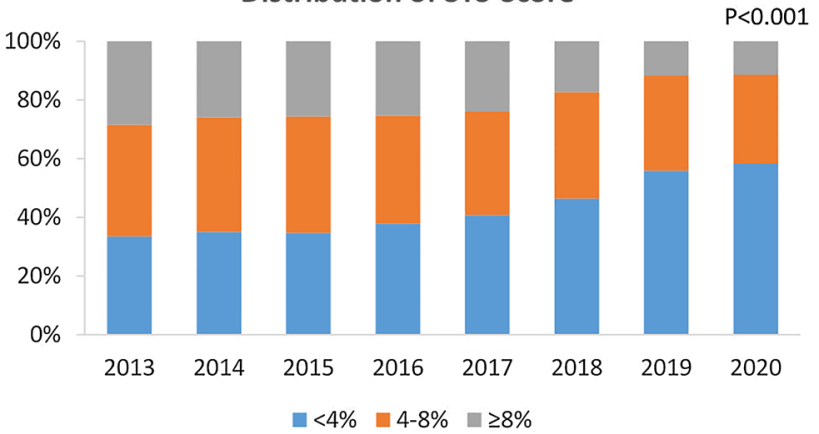

Fig. 1 Temporal trends of A: mean patient age; B: distribution of age; C: predicted surgical risk (STS-Score); and D: risk categories by STSscore. Mean patient age remained stable, whereas mean STS-score declined significantly, driven by a growing proportion of low-risk patients

\section{Baseline patient characteristics}

In line with decreasing predicted surgical risk, comorbidities of the analyzed TAVI patients changed over time. Accordingly, a significant decrease in diabetes mellitus, chronic obstructive pulmonary disease and previous cardiac surgery was observed. The percentage of patients with atrial fibrillation, coronary artery disease or previous stroke/TIA did not change in the observational period. A slight increase in previous myocardial infarction was observed. All baseline characteristics are shown in Table 1.

\section{Procedural complications and outcome}

Procedural characteristics and complications are shown in Supplementary Table 1 and Table 2 . Over the study period, there was a significant decline in bleeding (2013 23.5\%; $202012.1 \% ; P<0.001)$ and vascular complications (2013 $20.7 \% ; 202011.7 \% ; P<0.001)$ as well as a reduction in the rate of new permanent pacemaker implantation (PPI; 2013 $20.1 \% ; 202013.8 \%, P<0.001)$. The rare but severe complication of conversion to open heart surgery was reduced throughout the observational period (2013 5.5\%; 2020 $0.7 \%)$. Thirty-day mortality decreased significantly from initially $5.4-2.5 \%(P<0.001$; Table 2$)$, which was mainly driven by a significantly decreasing 30-day mortality in patients $>80$ years $(20136.5 \% ; 20202.1 \% ; P<0.001)$ and to a lesser extent in patients $75-80$ years $(20133.9 \% ; 2020$ $1.7 \%, P=0.325)$. Furthermore, 30-day mortality decreased significantly in low (STS <4\% $20132.8 \% ; 20201.2 \%$; $P=0.001)$ and intermediate risk patients (STS 4-8\% 2013 $6.2 \% ; 20201.8 \% ; P=0.001)$, but remained high in highrisk patients (STS $>8 \% 20137.5 \% ; 20206.9 \% ; P=0.778)$ (Fig. 3).

\section{Discussion}

The present study comprises the analysis of trends in baseline characteristics and procedural outcome in all-comer TAVI patients from five high-volume centers in Germany over a time period of 8 years, representing approximately $10 \%$ of the German TAVI procedures. The main findings are (1) The mean age of patients receiving TAVI is still over 80 years; (2) There is a clear trend to treat lower risk patients with TAVI with accordingly less comorbidities; (3) procedural complications and 30-day mortality decreased significantly.

The numbers of TAVI procedures performed increased steadily in the five TAVI centers studied herein, which has 

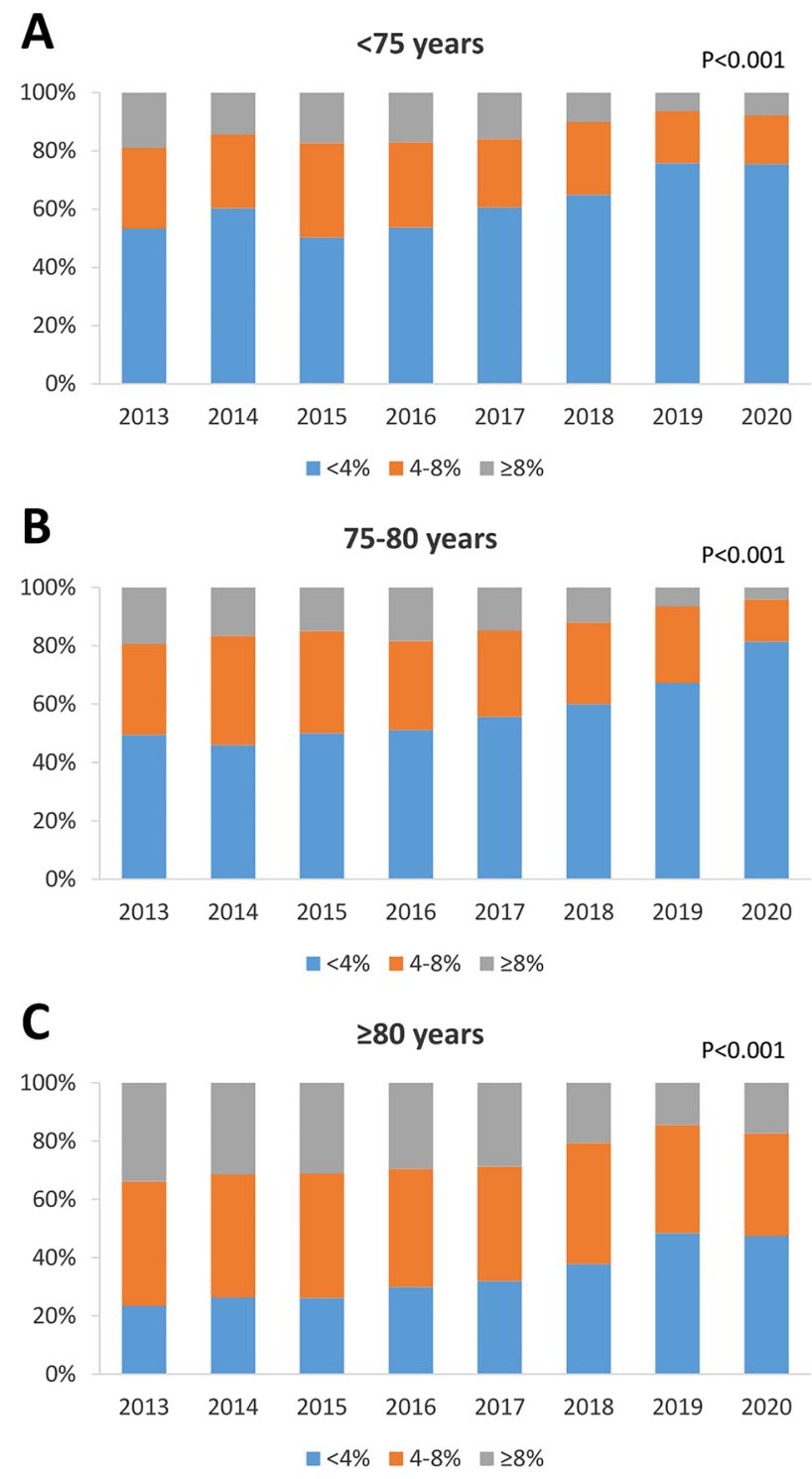

Fig. 2 Temporal trends of risk stratification by STS-Score in the age groups A: $<75$ years; $\mathbf{B}: 75-80$ years; $\mathbf{C}:>80$ years

also been observed in other large registries [11-15]. With a mean age of 81 years the investigated cohort is - with regard to age-more comparable to patients enrolled in the high and intermediate risk studies than to the recent randomized low-risk trials with a substantially lower mean age of 73 and 74 years, respectively $[16,17]$. Only the NOTION trial studied elderly low-risk patients with a mean age of approximately 79 years [18]. Surprisingly, the distribution of the patients according to their age remained almost unchanged over the observation period. The rate of patients with an age between 75 and 80 years was constantly around $22 \%$. At the beginning of 2020 the German national recommendations, endorsed by the German Societies of Cardiology and Cardio-thoracic surgery, recommended TAVI as first-line therapy in this age category [9]. The data of present analysis were collected until December 2020, so the uptake of this recommendation in clinical practice might not yet be fully reflected. The group of patients below 75 years receiving TAVI was constantly around $10 \%$. Of interest, at the beginning of the observational period the STS score of this group was significantly higher as compared to the more recent period. This might be explained by the fact that the decision to treat these relatively young patients with TAVI has initially been mainly driven by their surgical risk and their comorbidities. Whether factors not covered by the applied risk scores (e.g., porcelain aorta or sequelae of radiation) or more liberal indication for TAVI are responsible for the observed shift cannot be answered from our data.

The majority of patients ( $>60 \%$ ) was over 80 years, which is comparable to other registry data $[12-15,19]$. Since symptomatic severe aortic stenosis mostly occurs in the late seventh or eighth life decade, there are fewer young patients who need to undergo TAVI/SAVR which might also contribute to the observed age distribution. Furthermore, younger patients might also more often be treated surgically as they present frequently with anatomies less favorable for TAVI (for example bicuspid valves) or additional pathologies (e.g., coronary artery disease, multivalve disease, aortopathy) as their older counterparts.

The surgical risk based on the STS score overall reflects an intermediate risk cohort in our study. However, the mean STS score declined significantly during the observation period from $7.2 \%$ in 2013 to $4.6 \%$ in 2020 . The proportion of low-risk and intermediate-risk patients increased steadily whereas the percentage of high-risk patients decreased. In 2020 , more than $50 \%$ of the treated patients were classified as low-risk patients and less than $20 \%$ of the patients were classified as high-risk patients.

Our data reinforce the observation that recommendations of 2017 ESC/EACTS guidelines have been followed in clinical practice to prefer TAVI over SAVR in patients with increased surgical risk (STS score $>4$ ) and in the elderly ( $>80 / 85$ years) independent of their surgical risk [3].

The increase of low-risk patients in the age group $<75$ and 75-80 years is mainly pronounced in 2019 and 2020, which might be explained by a change in clinical practice probably based on the results of the Evolut and PARTNER 3 low-risk trials showing non-inferiority or even superiority of TAVI over SAVR $[16,17]$. Since these two groups made up for only $30 \%$ of the overall cohort, the impact of this change on age distribution is currently rather small. Whether a potential change in guideline recommendations leads to a more pronounced shift in the treated patient population needs to be investigated in the future.

The rate of vascular complications and bleeding events decreased significantly over time and is comparable to data from other studies $[13,19]$. Improvements and downsizing 
Table 1 Patient baseline characteristics by year

\begin{tabular}{|c|c|c|c|c|c|c|c|c|c|}
\hline Year & 2013 & 2014 & 2015 & 2016 & 2017 & 2018 & 2019 & 2020 & $P$ value \\
\hline$N$ & 1071 & 1212 & 1512 & 1723 & 2208 & 2234 & 2388 & 2996 & \\
\hline Age (years) & $81.0 \pm 6.1$ & $81.1 \pm 5.8$ & $80.9 \pm 6.2$ & $80.8 \pm 6.3$ & $80.9 \pm 6.2$ & $80.9 \pm 6.2$ & $80.9 \pm 6.1$ & $80.8 \pm 6.4$ & 0.976 \\
\hline$<75$ years & $137(12.8)$ & $146(12.0)$ & $185(12.2)$ & $229(13.3)$ & $251(11.4)$ & $268(12.0)$ & $281(11.8)$ & 408 (13.6) & 0.669 \\
\hline $75-80$ years & $259(24.2)$ & $283(23.3)$ & $354(23.4)$ & $391(22.7)$ & $516(23.4)$ & $532(23.8)$ & $541(22.7)$ & $673(22.5)$ & \\
\hline$\geq 80$ years & $675(63.0)$ & $783(64.6)$ & $973(64.4)$ & $1103(64.0)$ & $1441(65.3)$ & $1434(64.2)$ & $1566(65.6)$ & 1915 (63.9) & \\
\hline STS-Score (\%) & $7.2 \pm 6.2$ & $6.8 \pm 5.9$ & $6.8 \pm 6.1$ & $6.5 \pm 5.5$ & $6.2 \pm 5.4$ & $5.5 \pm 4.3$ & $4.6 \pm 3.8$ & $4.6 \pm 3.7$ & $<0.001$ \\
\hline$<4 \%$ & $359(33.5)$ & $424(35.0)$ & $525(34.7)$ & $653(37.9)$ & 899 (40.7) & $1036(46.4)$ & $1335(55.9)$ & $1737(58.0)$ & $<0.001$ \\
\hline $4-8 \%$ & $407(38.0)$ & $474(39.1)$ & 599 (39.6) & $634(36.8)$ & 779 (35.3) & $811(36.3)$ & 773 (32.4) & $903(30.1)$ & \\
\hline$\geq 8 \%$ & $305(28.5)$ & $314(25.9)$ & 388 (25.7) & $436(25.3)$ & $530(24.0)$ & $387(17.3)$ & $280(11.7)$ & $341(11.4)$ & \\
\hline EuroSCORE II (\%) & $7.4 \pm 6.7$ & $7.4 \pm 7.4$ & $7.8 \pm 7.9$ & $7.1 \pm 7.1$ & $6.7 \pm 7.2$ & $6.2 \pm 6.3$ & $5.4 \pm 5.7$ & $5.2 \pm 5.3$ & $<0.001$ \\
\hline Female sex & $584(54.5)$ & $666(55.0)$ & $790(52.2)$ & $909(52.8)$ & $1140(51.6)$ & $1168(52.3)$ & $1170(49.0)$ & $1374(45.9)$ & $<0.001$ \\
\hline Hypertension & $996(93.0)$ & $1118(92.2)$ & $1385(91.7)$ & $1393(90.6)$ & $2000(90.6)$ & $2003(90.0)$ & $2069(86.9)$ & $2600(86.8)$ & $<0.001$ \\
\hline Diabetes & $408(38.1)$ & $439(36.2)$ & $521(34.5)$ & $498(32.4)$ & 787 (35.7) & 755 (33.9) & $775(32.5)$ & $1026(34.2)$ & 0.119 \\
\hline GFR (ml/min) & $56 \pm 21$ & $56 \pm 19$ & $55 \pm 21$ & $55 \pm 20$ & $56 \pm 20$ & $56 \pm 20$ & $56 \pm 19$ & $57 \pm 20$ & 0.053 \\
\hline Dialysis & $34(3.2)$ & $38(3.1)$ & $59(4.4)$ & $51(3.3)$ & $43(2.0)$ & $59(2.7)$ & $56(2.4)$ & $78(2.7)$ & 0.013 \\
\hline COPD & $298(31.1)$ & $333(29.4)$ & $409(29.1)$ & $448(27.0)$ & $510(25.2)$ & $344(15.7)$ & $444(19.6)$ & $373(18.8)$ & $<0.001$ \\
\hline Peripheral artery disease & $287(26.8)$ & $343(28.3)$ & $399(26.4)$ & $418(27.2)$ & $548(24.8)$ & $542(24.4)$ & $647(27.2)$ & $676(22.6)$ & $<0.001$ \\
\hline Coronary artery disease & $588(54.9)$ & $645(53.2)$ & $722(53.6)$ & $931(54.1)$ & $1172(53.1)$ & $1411(63.4)$ & $1263(53.1)$ & $1851(58.8)$ & $<0.001$ \\
\hline $\begin{array}{l}\text { Previous myocardial } \\
\text { infarction }\end{array}$ & $166(15.5)$ & $162(13.4)$ & $228(15.1)$ & 209 (13.6) & $353(16.0)$ & $468(21.0)$ & $624(26.3)$ & $609(20.3)$ & $<0.001$ \\
\hline Previous cardiac surgery & $216(20.2)$ & $234(19.3)$ & $301(19.9)$ & $208(15.3)$ & $224(14.7)$ & $237(15.0)$ & $316(13.3)$ & $389(13.0)$ & $<0.001$ \\
\hline Atrial fibrillation & $428(40.0)$ & $485(40.0)$ & 588 (38.9) & $657(38.2)$ & $852(38.8)$ & $945(42.7)$ & $934(39.3)$ & $1150(38.4)$ & 0.065 \\
\hline Previous stroke/TIA & $131(12.2)$ & $147(12.1)$ & $193(12.8)$ & $176(11.5)$ & $163(7.4)$ & $278(12.5)$ & $240(10.1)$ & $316(10.6)$ & $<0.001$ \\
\hline
\end{tabular}

Values are mean $\pm \mathrm{SD}$ or $n(\%)$

$C O P D$ chronic obstructive pulmonary disease, GFR glomerular filtration rate

Table 2 Periprocedural complications by year

\begin{tabular}{|c|c|c|c|c|c|c|c|c|c|}
\hline Year & 2013 & 2014 & 2015 & 2016 & 2017 & 2018 & 2019 & 2020 & $P$ value \\
\hline$N$ & 1071 & 1212 & 1512 & 1723 & 2208 & 2234 & 2388 & 2996 & \\
\hline Vascular complication & $221(20.7)$ & $203(16.7)$ & $314(20.8)$ & $241(14.0)$ & $319(14.5)$ & $334(15.8)$ & $238(12.2)$ & $352(11.7)$ & $<0.001$ \\
\hline Major & $121(11.3)$ & $72(5.9)$ & $65(4.3)$ & $48(2.8)$ & $77(3.5)$ & $73(3.4)$ & $52(2.7)$ & $64(2.1)$ & $<0.001$ \\
\hline Bleeding & $251(23.5)$ & $245(20.2)$ & $320(21.2)$ & $148(8.6)$ & $224(10.2)$ & $270(12.7)$ & $195(8.8)$ & $362(12.1)$ & $<0.001$ \\
\hline Major/life-threatening & $196(18.3)$ & $168(13.9)$ & $145(9.6)$ & $87(5.1)$ & $99(4.5)$ & $121(5.7)$ & $83(3.7)$ & $99(3.3)$ & $<0.001$ \\
\hline New permanent pacemaker & $184(20.1)$ & $236(22.2)$ & $235(18.5)$ & $244(16.3)$ & $270(14.0)$ & $256(13.2)$ & $236(12.6)$ & $357(13.8)$ & $<0.001$ \\
\hline Stroke & $38(4.0)$ & $29(2.7)$ & $45(3.4)$ & $43(2.8)$ & $36(1.9)$ & $35(2.0)$ & $46(2.9)$ & $78(3.0)$ & 0.017 \\
\hline Conversion to open surgery & $30(5.5)$ & $59(8.8)$ & $55(6.9)$ & $75(7.7)$ & $49(4.5)$ & $39(3.4)$ & $28(1.7)$ & $8(0.7)$ & $<0.001$ \\
\hline In-hospital mortality & $59(5.5)$ & $53(4.4)$ & $60(4.0)$ & $51(3.0)$ & $39(1.8)$ & $42(2.0)$ & $51(2.1)$ & $48(1.6)$ & $<0.001$ \\
\hline Thirty-day mortality & $59(5.5)$ & $54(4.5)$ & $64(4.2)$ & $51(3.2)$ & $42(3.0)$ & $61(2.7)$ & $54(2.5)$ & $60(2.1)$ & $<0.001$ \\
\hline \multicolumn{10}{|l|}{ Thirty-day mortality by age } \\
\hline$<75$ years & $4(2.9)$ & $5(3.4)$ & $8(4.3)$ & $6(2.9)$ & $4(2.6)$ & $6(2.2)$ & $7(2.7)$ & $10(2.1)$ & 0.949 \\
\hline $75-80$ years & $10(3.9)$ & $11(3.9)$ & $13(3.7)$ & $9(2.6)$ & $7(2.4)$ & $9(1.7)$ & $9(1.9)$ & $11(1.7)$ & 0.167 \\
\hline$\geq 80$ years & $44(6.5)$ & $38(4.9)$ & $43(4.4)$ & $36(3.5)$ & $31(3.2)$ & $46(3.2)$ & $38(2.6)$ & $39(2.1)$ & $<0.001$ \\
\hline \multicolumn{10}{|c|}{ Thirty-day mortality by STS-score } \\
\hline$<4 \%$ & $10(2.8)$ & $17(4.0)$ & $13(2.5)$ & $12(2.0)$ & $12(1.8)$ & $14(1.4)$ & $12(1.0)$ & $21(1.2)$ & 0.001 \\
\hline $4-8 \%$ & $25(6.2)$ & $18(3.8)$ & $17(2.8)$ & $10(1.7)$ & $14(2.9)$ & $19(2.3)$ & $19(2.6)$ & $16(1.8)$ & 0.001 \\
\hline$\geq 8 \%$ & $23(7.5)$ & $19(6.1)$ & $34(8.8)$ & 29 (7.6) & $16(6.0)$ & $28(7.2)$ & $23(9.2)$ & $23(6.9)$ & 0.778 \\
\hline
\end{tabular}

Values are $n(\%)$ 
A

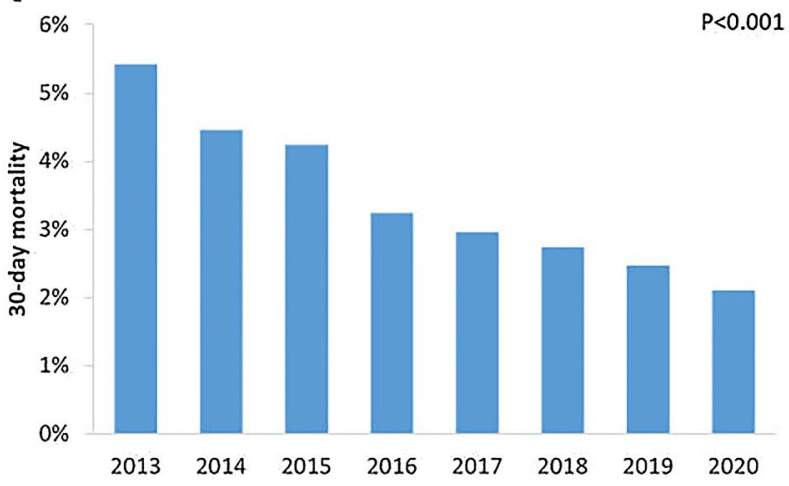

B

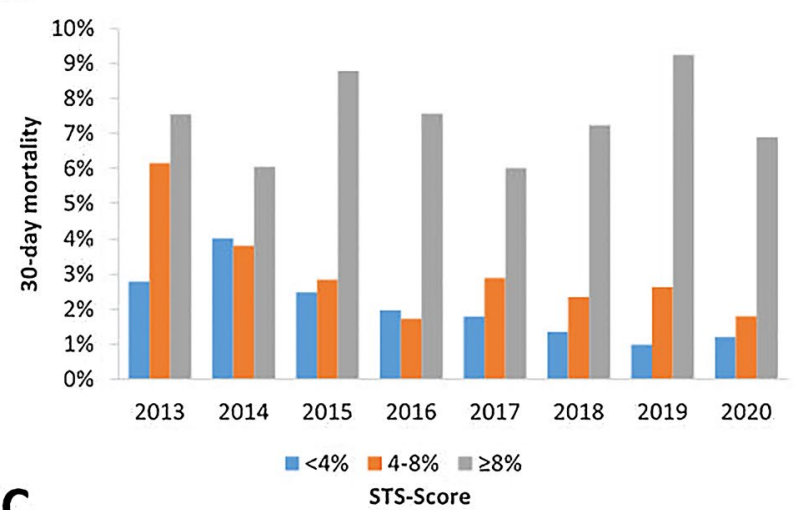

C

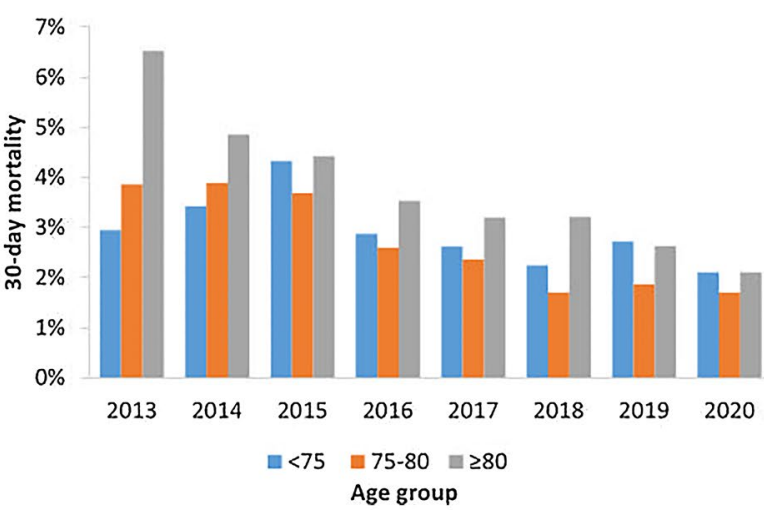

Fig. 3 Trend of 30-day mortality. A: overall cohort $(P<0.001)$; $B$ : according to STS-risk score group $(<4 \%: P=0.001 ; 4-8 \%$ : $P=0.001 ; \geq 8 \%: P=0.778) C$ : according to age group ( $<75$ years: $P=0.949 ; 75-80: P=0.167 ; \geq 80: P<0.001)$

in vascular sheaths for almost all currently available TAVI devices are contributing to this finding as does the increasing operators' experience. The PPI rate declined significantly in our population, however there are conflicting data within the literature with some studies even showing increasing rates of PPI over time [14, 20-22]. Several factors including baseline conduction disturbances, sizing, implantation depth, membranous septum length, and calcium distribution have been identified as important determining factors of the subsequent need for pacemaker implantation [23-25]. Accordingly, changes in implantation technique, namely cusp-overlap for self-expanding TAVI, and an individualized TAVI device selection have been progressively adopted in clinical practice in the participating centers over the recent years, possibly resulting in declining pacemaker rates in the current analysis. In addition to that, low-risk patients have been shown to have a lower risk for conduction disturbances requiring new PPI [22].

Thirty-day mortality declined significantly over the observational period, a phenomenon which has been reported elsewhere [12-14]. The decline was mainly observed in the patient group $>80$ years and in intermediate risk patients. Operators' experience and a more standardized less invasive procedure might be the main contributors to this observation. Of note, in high-risk patients the 30-day mortality rate remained almost unchanged high at approximately $8 \%$, which is an important information for patient selection and patient counselling in daily clinical practice.

In low- and intermediate-risk patients, 30-day mortality in this all-comer patient population was higher as in randomized trials and basically unchanged over the last 5 years. In contrast to the highly selected patients within randomized trials, an all-comers population was included in this study that more likely represents real-world practice.

Thirty-day mortality in the group of 75-80 years declined significantly and was stable at about $2 \%$ throughout the last 3 years. Of interest, 30 -day mortality in patients $<75$ years is higher (approximately 3\%) as compared to the group of $75-80$ years, as is the proportion of patients with an STS score $\geq 8$. Consequently, in this relatively young patient group the decision for TAVI seems to be based on high surgical risk or other issues not covered by the risk scores and not a sign of increased use of TAVI in younger patients.

\section{Limitations}

This is an observational analysis with all its inherent limitations. All parameters were site reported and only German sites were included. Detailed information on patient selection criteria from each center were not available.

\section{Conclusions}

This analysis provides important insights into current clinical practice. In five high volume centers, from 2013 to 2020, there has been a relevant expansion of TAVI procedures towards patients with lower surgical risk despite advanced age, which remained $>80$ years over time. Elderly patients can be treated safely with TAVI irrespective of their predicted surgical risk. The often-expressed criticism of an 
unjustified expansion of TAVI indications towards young low-risk patients cannot be confirmed from this data.

Supplementary Information The online version contains supplementary material available at https://doi.org/10.1007/s00392-021-01963-3.

Funding Open Access funding enabled and organized by Projekt DEAL. M. Adam, G. Nickenig, M. Kelm, and S. Baldus, are supported by the Deutsche Forschungsgemeinschaft (German Research Foundation; SFB TRR 259/1).

\section{Declarations}

Conflict of interest MAW reports that his hospital receives speakers' honoraria and/or consultancy fees on his behalf from Boston Scientific, Edwards Lifesciences and Medtronic. S. Bleiziffer received speaker honoraria from Medtronic and Boston Scientific. VV and MK have received consulting fees, travel expenses, or study honoraria from Medtronic and Edwards Lifesciences. MA reports consulting fees from Edwards Lifescience and Boston Scientific, and institutional grants and consulting fees from Medtronic during the conduct of the study. TKR received speaker's honoraria from Abbott, Boston Scientific, Edwards Lifesciences and Medtronic and she is a proctor for Edwards Lifesciences. All other authors declare no conflict of interest.

Open Access This article is licensed under a Creative Commons Attribution 4.0 International License, which permits use, sharing, adaptation, distribution and reproduction in any medium or format, as long as you give appropriate credit to the original author(s) and the source, provide a link to the Creative Commons licence, and indicate if changes were made. The images or other third party material in this article are included in the article's Creative Commons licence, unless indicated otherwise in a credit line to the material. If material is not included in the article's Creative Commons licence and your intended use is not permitted by statutory regulation or exceeds the permitted use, you will need to obtain permission directly from the copyright holder. To view a copy of this licence, visit http://creativecommons.org/licenses/by/4.0/.

\section{References}

1. Smith CR, Leon MB, Mack MJ, Miller DC, Moses JW, Svensson LG, Tuzcu EM, Webb JG, Fontana GP, Makkar RR et al (2012) Transcatheter versus surgical aortic-valve replacement in high-risk patients. Surv Anesthesiol. https://doi.org/10.1097/01.sa.00004 10147.99581.d4

2. Adams DH, Popma JJ, Reardon MJ, Yakubov SJ, Coselli JS, Deeb GM, Gleason TG, Buchbinder M, Hermiller J, Kleiman NS et al (2014) Transcatheter aortic-valve replacement with a self-expanding prosthesis. N Engl J Med 370:1790-1798. https://doi.org/10. 1056/nejmoa1400590

3. Baumgartner H, Falk V, Bax JJ, De Bonis M, Hamm C, Holm PJ, Iung B, Lancellotti P, Lansac E, Mu DR et al (2017) 2017 ESC/ EACTS Guidelines for the management of valvular heart disease the task force for the management of valvular heart disease. Eur Heart J. https://doi.org/10.1093/eurheartj/ehx391

4. Reardon MJ, Van Mieghem NM, Popma JJ, Kleiman NS, Søndergaard L, Mumtaz M, Adams DH, Deeb GM, Maini B, Gada H et al (2017) Surgical or transcatheter aortic-valve replacement in intermediate-risk patients. N Engl J Med 376:1321-1331. https:// doi.org/10.1056/NEJMoa1700456
5. Leon MB, Smith CR, Mack MJ, Makkar RR, Svensson LG, Kodali SK, Thourani VH, Tuzcu EM, Miller DC, Herrmann HC et al (2016) Transcatheter or surgical aortic-valve replacement in intermediate-risk patients. N Engl J Med 374:1609-1620. https:// doi.org/10.1056/nejmoa1514616

6. Sedaghat A, Sinning JM, Vasa-Nicotera M, Ghanem A, Hammerstingl C, Grube E, Nickenig G, Werner N (2013) The revised EuroSCORE II for the prediction of mortality in patients undergoing transcatheter aortic valve implantation. Clin Res Cardiol 102:821-829. https://doi.org/10.1007/S00392-013-0596-8

7. Abugroun A, Daoud H, Abdel-Rahman ME, Hallak O, Igbinomwanhia E, Sanchez A, Shroff A, Klein LW (2020) National trends of outcomes in transcatheter aortic valve replacement (TAVR) through transapical versus endovascular approach: from the national inpatient sample (NIS). Cardiovasc Revascularization Med 21:964-970. https://doi.org/10.1016/j.carrev.2020.05.010

8. Winter MP, Bartko P, Hofer F, Zbiral M, Burger A, Ghanim B, Kastner J, Lang IM, Mascherbauer J, Hengstenberg C et al (2020) Evolution of outcome and complications in TAVR: a meta-analysis of observational and randomized studies. Sci Rep. https://doi. org/10.1038/s41598-020-72453-1

9. Kuck KH, Bleiziffer S, Eggebrecht H, Ensminger S, Frerker C, Möllmann H, Nef H, Thiele H, Treede H, Wimmer-Greinecker $G$ et al (2020) Consensus paper of the german cardiac society (DGK) and the German society for thoracic and cardiovascular surgery (DGTHG) on transcatheter aortic valve implantation (TAVI) 2020. Kardiologe 14:182-204. https://doi.org/10.1007/ s12181-020-00398-w

10. Pieter Kappetein A, Head SJ, Généreux P, Piazza N, Van Mieghem NM, Blackstone EH, Brott TG, Cohen DJ, Cutlip DE, Van Es GA et al (2012) Updated standardized endpoint definitions for transcatheter aortic valve implantation: the valve academic research consortium-2 consensus document. EuroIntervention 8:782-795. https://doi.org/10.17660/ActaHortic.2001.566.72

11. Deutscher Herzbericht 2019 (2020) Available at: https://www. herzstiftung.de/service-und-aktuelles/publikationen-und-medien/ herzbericht. Accessed 10 Jun 2021

12. Carroll JD, Mack MJ, Vemulapalli S, Herrmann HC, Gleason TG, Hanzel G, Deeb GM, Thourani VH, Cohen DJ, Desai N et al (2020) STS-ACC TVT registry of transcatheter aortic valve replacement. J Am Coll Cardiol 76:2492-2516. https://doi.org/ 10.1016/j.jacc.2020.09.595

13. Stortecky S, Franzone A, Heg D, Tueller D, Noble S, Pilgrim T, Jeger R, Toggweiler S, Ferrari E, Nietlispach F et al (2019) Temporal trends in adoption and outcomes of transcatheter aortic valve implantation: a Swiss TAVI Registry analysis. Eur Hear J Qual Care Clin Outcomes 5:242-251. https://doi.org/10.1093/ ehjqcco/qcy048

14. Auffret V, Lefevre T, Van Belle E, Eltchaninoff H, Iung B, Koning R, Motreff P, Leprince P, Verhoye JP, Manigold T et al (2017) Temporal trends in transcatheter aortic valve replacement in France: FRANCE 2 to FRANCE TAVI. J Am Coll Cardiol 70:42-55. https://doi.org/10.1016/j.jacc.2017.04.053

15. Ludman PF (2019) UK TAVI registry. Heart 105:S2-S5. https:// doi.org/10.1136/heartjnl-2018-313510

16. Mack MJ, Leon MB, Thourani VH, Makkar R, Kodali SK, Russo M, Kapadia SR, Malaisrie SC, Cohen DJ, Pibarot P et al (2019) Transcatheter aortic-valve replacement with a balloon-expandable valve in low-risk patients. N Engl J Med 380:1695-1705. https:// doi.org/10.1056/NEJMoa1814052

17. Popma JJ, Deeb GM, Yakubov SJ, Mumtaz M, Gada H, O’Hair D, Bajwa T, Heiser JC, Merhi W, Kleiman NS et al (2019) Transcatheter aortic-valve replacement with a self-expanding valve in low-risk patients. N Engl J Med 380:1706-1715. https://doi.org/ 10.1056/NEJMoa1816885 
18. Thyregod HGH, Steinbrüchel DA, Ihlemann N, Nissen H, Kjeldsen BJ, Petursson P, Chang Y, Franzen OW, Engstrøm T, Clemmensen $P$ et al (2015) Transcatheter versus surgical aortic valve replacement in patients with severe aortic valve stenosis: 1-year results from the all-comers NOTION randomized clinical trial. J Am Coll Cardiol 65:2184-2194. https://doi.org/10.1016/j.jacc. 2015.03.014

19. Saad AM, Kassis N, Isogai T, Gad MM, Ahuja KR, Abdelfattah O, Shekhar S, Farwati M, Yun JJ, Krishnaswamy A et al (2021) Trends in outcomes of transcatheter and surgical aortic valve replacement in the United States (2012-2017). Am J Cardiol 141:79-85. https://doi.org/10.1016/j.amjcard.2020.10.065

20. Barbanti M, Buccheri S, Rodés-Cabau J, Gulino S, Généreux P, Pilato G, Dvir D, Picci A, Costa G, Tamburino C et al (2017) Transcatheter aortic valve replacement with new-generation devices: a systematic review and meta-analysis. Int J Cardiol 245:83-89. https://doi.org/10.1016/j.ijcard.2017.07.083

21. Al-Ogaili A, Fugar S, Okoh A, Kolkailah AA, Al Hashemi N, Ayoub A, Russo MJ, Kavinsky CJ (2019) Trends in complete heart block after transcatheter aortic valve replacement: a population based analysis. Catheter Cardiovasc Interv 94:773-780. https://doi.org/10.1002/ccd.28156
22. Eliav R, Elitzur Y, Planer D, Beeri R, Gilon D, Shuvy M, Luria D, Danenberg H, Perlman GY (2020) Predictors for permanent pacemaker implantation following transcatheter aortic valve implantation: trends over the past decade. J Interv Card Electrophysiol. https://doi.org/10.1007/s10840-020-00902-y

23. Mauri V, Deuschl F, Frohn T, Schofer N, Linder M, Kuhn E, Schaefer A, Rudolph V, Madershahian N, Conradi L et al (2018) Predictors of paravalvular regurgitation and permanent pacemaker implantation after TAVR with a next-generation selfexpanding device. Clin Res Cardiol. https://doi.org/10.1007/ s00392-018-1235-1

24. Mauri V, Reimann A, Stern D, Scherner M, Kuhn E, Rudolph V, Rosenkranz S, Eghbalzadeh K, Friedrichs K, Wahlers T et al (2016) Predictors of permanent pacemaker implantation after transcatheter aortic valve replacement with the SAPIEN 3. JACC Cardiovasc Interv. https://doi.org/10.1016/j.jcin.2016.08.034

25. Maier O, Piayda K, Afzal S, Polzin A, Westenfeld R, Jung C, Zeus T, Antoch G, Kelm M, Veulemans V (2021) Computed tomography derived predictors of permanent pacemaker implantation after transcatheter aortic valve replacement: a meta-analysis. Catheter Cardiovasc Interv. https://doi.org/10.1002/CCD.29805

\section{Authors and Affiliations}

\section{Victor Mauri ${ }^{1} \mathbb{D} \cdot$ Mohamed Abdel-Wahab $^{2} \cdot$ Sabine Bleiziffer $^{3} \cdot$ Verena Veulemans $^{4} \cdot$ Alexander Sedaghat $^{5}$. Matti Adam ${ }^{1} \cdot$ Georg Nickenig ${ }^{5} \cdot$ Malte Kelm $^{4} \cdot$ Holger Thiele $^{2} \cdot$ Stephan Baldus $^{1} \cdot$ Tanja K. Rudolph $^{6}$}

1 Department of Cardiology, Faculty of Medicine, Heart Center, University of Cologne, Cologne, Germany

2 Department of Cardiology, Heart Center Leipzig at University of Leipzig, Leipzig, Germany

3 Department of Thoracic and Cardiovascular Surgery, Heart and Diabetes Center North Rhine-Westphalia, Ruhr-University Bochum, Bad Oeynhausen, Germany
4 Department of Cardiology, Pulmonology and Vascular Medicine, Heart Center Düsseldorf, Heinrich Heine University, Medical Faculty, Düsseldorf, Germany

5 Department of Medicine II, Heart Center Bonn, University Hospital Bonn, Bonn, Germany

6 Department of General and Interventional Cardiology, Heart- and Diabetes Center North Rhine-Westphalia, Ruhr-University Bochum, Bad Oeynhausen, Germany 